\title{
Predicting and managing sepsis in burn patients: current perspectives
}

\author{
This article was published in the following Dove Press journal: \\ Therapeutics and Clinical Risk Management \\ 29 August 2017 \\ Number of times this article has been viewed
}

\author{
Omar Nunez Lopez ${ }^{1,2}$ \\ Janos Cambiaso-Daniel ${ }^{1-3}$ \\ Ludwik K Branski ${ }^{1,2}$ \\ William B Norbury ${ }^{1,2}$ \\ David N Herndon 1,2,4 \\ 'Department of Surgery, University \\ of Texas Medical Branch, ${ }^{2}$ Shriners \\ Hospitals for Children, Galveston, \\ TX, USA; ${ }^{3}$ Division of Plastic, \\ Aesthetic and Reconstructive Surgery, \\ Department of Surgery, Medical \\ University of Graz, Graz, Austria; \\ ${ }^{4}$ Department of Pediatrics, University \\ of Texas Medical Branch, Galveston, \\ TX, USA
}

Correspondence: David N Herndon Department of Surgery, University of Texas Medical Branch, 815 Market St, TX 77550, USA

$\mathrm{Tel}+\mid 409770673$ |

Fax +I 4097706919

Email dherndon@utmb.edu

\begin{abstract}
Modern burn care has led to unprecedented survival rates in burn patients whose injuries were fatal a few decades ago. Along with improved survival, new challenges have emerged in the management of burn patients. Infections top the list of the most common complication after burns, and sepsis is the leading cause of death in both adult and pediatric burn patients. The diagnosis and management of sepsis in burns is complex as a tremendous hypermetabolic response secondary to burn injury can be superimposed on systemic infection, leading to organ dysfunction. The management of a septic burn patient represents a challenging scenario that is commonly encountered by providers caring for burn patients despite preventive efforts. Here, we discuss the current perspectives in the diagnosis and treatment of sepsis and septic shock in burn patients.
\end{abstract}

Keywords: burn injury, thermal injury, burn sepsis, procalcitonin, antibiotics, biomarkers, cytokines

\section{Introduction}

Modern burn care has led to unprecedented survival rates for burn patients whose injuries were considered fatal a few decades ago. Improved survival has been met with new challenges in the management of burn patients. Infections are the most common complications after burns, with pneumonia, urinary tract infections, and cellulitis being the most frequent complications in hospitalized burn patients. ${ }^{1}$ Furthermore, sepsis is the leading cause of mortality in adult and pediatric burn patients. Rates of sepsis-related death are $50 \%-84 \%$ in adult burn patients and $\sim 55 \%$ in pediatric burn patients. ${ }^{2-5}$

Burn injury alters the integrity of the skin, the primary barrier against pathogens found in the environment. Therefore, thermal injury, itself, increases the risk of infections. In addition, a subsequent state of systemic inflammation and burn-induced immunosuppression leads to an even greater susceptibility to infections and sepsis. ${ }^{6-8}$

No single validated diagnostic test for sepsis currently exists, and identification of sepsis relies on the use of combined clinical and laboratory criteria. ${ }^{9}$ Furthermore, the diagnosis of sepsis in patients with severe burns $(>20 \%$ total body surface area [TBSA]) is particularly complicated by the overlap of clinical signs of the postburn hypermetabolic response with those of sepsis. ${ }^{10}$

Optimal treatment of sepsis (in burned and nonburn patients) depends on early diagnosis and includes prompt administration of antimicrobials as well as management of hemodynamic alterations and other organ dysfunctions. ${ }^{11}$ Delays in the initiation of antimicrobial treatment may be associated with greater mortality and poorer outcomes. ${ }^{12,13}$ Administration of antimicrobial therapy during the first hour of hypotension in adult patients with septic shock is associated with greater survival. ${ }^{14}$ Therefore, high suspicion, timely diagnosis, and rapid treatment of sepsis are key 
elements to increasing the odds of favorable outcomes in a population at risk for infectious complications.

\section{Sepsis: unsteady definitions}

Despite significant advances in understanding the biologic alterations that accompany sepsis, this pathophysiological phenomenon continues to be incompletely understood. ${ }^{9}$ Indeed, the definition of sepsis has evolved over time. The initial American College of Chest Physicians/Society of Critical Care Medicine (ACCP/SCCM) definition published in 1991 focused mainly on systemic inflammation and considered sepsis a continuum of the systemic inflammatory response syndrome (SIRS) to infection. Sepsis with organ dysfunction was termed "severe sepsis," while "septic shock" was defined as "sepsis-induced hypotension persisting despite adequate fluid resuscitation." 15 In 2001, the definition was revised without substantial changes. ${ }^{16}$

Considering that most of the patients with large burns meet SIRS criteria, the early definitions of sepsis were overly inclusive and of limited benefit in identifying burn patients with sepsis. The American Burn Association (ABA) held a multidisciplinary consensus conference in 2007 to define sepsis in burn patients. It recognized the irrelevance of the term "severe sepsis" and incorporated elements of organ dysfunction into the diagnostic criteria. ${ }^{10}$

The 2007 ABA consensus report lacks a strict definition of sepsis but proposes that the presence of at least 3 clinical or laboratory criteria (Table 1) should trigger concern of infection and should lead to the presumptive diagnosis of sepsis. After these conditions are met, the experts recommend searching for a source of infection, emphasizing that a definitive diagnosis of sepsis must be accompanied by documented evidence of infection (positive culture, identification of pathologic source, or clinical response to antimicrobials). ${ }^{10}$

Most recently, in 2016, the international consensus (sepsis-3) substantially modified the definition. Sepsis was defined as a "life-threatening organ dysfunction caused by a dysregulated host response to infection." In other words, it is regarded as a dysregulated response to infection manifested as organ dysfunction. Therefore, the term severe sepsis is now considered obsolete. ${ }^{9}$

Adoption of the new definition of sepsis from the latest international consensus (sepsis-3) by the burn community bears consideration. Similar to the 2007 ABA sepsis definition, the sepsis-3 diagnostic criteria include evidence of organ dysfunction. ${ }^{9,10}$ The sepsis-3 criteria might be more practical in clinical practice because they entail the use of a standardized approach (ie, Sequential Organ Failure Assessment [SOFA] score) to assess the clinical criteria of organ dysfunction ${ }^{17}$ (Table 2). The SOFA score is associated with greater prognostic accuracy for in-hospital mortality of patients with suspected infection in the intensive care unit (ICU). ${ }^{18}$ In addition, a simplified version of the SOFA score, the quick SOFA score is a validated mortality predictor for patients with suspected infection outside the ICU. ${ }^{18,19}$ Use of these score systems would not only be practical, but would also help operationalize the diagnosis of sepsis in burn patients. However, we acknowledge that these scores have not been validated in burn patients.

\section{Sepsis in burn patients: diagnostic and prognostic tools}

The importance of early diagnosis of sepsis and prompt initiation of treatment cannot be overemphasized. Research efforts to identify biomarkers that can assist in the diagnosis

Table I ABA 2007 diagnostic criteria of sepsis in burn patients

\begin{tabular}{|c|c|c|}
\hline & Children & Adults \\
\hline Progressive tachycardia & $\begin{array}{l}>2 \text { SD age-specific norms ( } 85 \% \text { age-adjusted } \\
\text { maximum heart rate) }\end{array}$ & $>110 b p m^{a}$ \\
\hline Progressive tachypnea & $\begin{array}{l}>2 \text { SD age-specific norms ( } 85 \% \text { age-adjusted } \\
\text { maximum respiratory rate) }\end{array}$ & $\begin{array}{l}>25 \text { bpm }^{\mathrm{b}} \text { (not ventilated) or }>12 \mathrm{~L} / \mathrm{min} \\
\text { (ventilated) }\end{array}$ \\
\hline $\begin{array}{l}\text { Thrombocytopenia (applicable only } 3 \text { days } \\
\text { after initial resuscitation) }\end{array}$ & $<2$ SD age-specific norms & $<100 \times 10^{3} / \mu \mathrm{L}$ \\
\hline $\begin{array}{l}\text { Hyperglycemia (without preexisting diabetes } \\
\text { mellitus) }\end{array}$ & $\begin{array}{l}>200 \mathrm{mg} / \mathrm{dL} \text { (without treatment) or } \\
\text { insulin resistance: }>25 \% \text { increase in insulin } \\
\text { requirements in } 24 \text { hours }\end{array}$ & $\begin{array}{l}>200 \mathrm{mg} / \mathrm{dL} \text { (without treatment) or insulin } \\
\text { resistance: }>7 \mathrm{IU} / \text { hour IV insulin }\end{array}$ \\
\hline Inability to continue enteral feedings $>24$ hours & $\begin{array}{l}\text { Abdominal distension, enteral feeding } \\
\text { intolerance (residual }>150 \mathrm{~mL} / \mathrm{h} \text { ), } \\
\text { uncontrollable diarrhea }\end{array}$ & $\begin{array}{l}\text { Abdominal distension, enteral feeding } \\
\text { intolerance (residual }>2 \times \text { feeding rate), } \\
\text { uncontrollable diarrhea }\end{array}$ \\
\hline
\end{tabular}

Notes: ${ }^{a}$ Beats per minute; 'Breaths per minute. Reproduced with permission from Greenhalgh DG, Saffle JR, Holmes JH 4th, et al. American Burn Association consensus conference to define sepsis and infection in burns. J Burn Care Res. 2007;28(6):776-790, http://journals.Iww.com/burncareresearch/Abstract/2007/II000/American_Burn_ Association_Consensus_Conference_to.2.aspx. ${ }^{10}$

Abbreviations: ABA, American Burn Association; SD, standard deviation. 
Table 2 Sepsis-related organ failure assessment (SOFA) score ${ }^{17}$

\begin{tabular}{|c|c|c|c|c|c|}
\hline & \multicolumn{5}{|l|}{ Score } \\
\hline & 0 & $\mathbf{I}$ & 2 & 3 & 4 \\
\hline \multicolumn{6}{|l|}{ Respiratory system } \\
\hline $\mathrm{PaO}_{2} / \mathrm{FiO}_{2}(\mathrm{mmHg})$ & $\geq 400$ & $<400$ & $<300$ & $\begin{array}{l}<200 \text { with respiratory } \\
\text { support }\end{array}$ & $\begin{array}{l}<100 \text { with respiratory } \\
\text { support }\end{array}$ \\
\hline \multicolumn{6}{|l|}{ Hepatic system } \\
\hline Bilirubin (mg/dL) & $<\mathrm{I} .2$ & $1.2-1.9$ & $2.0-5.9$ & $6.0-11.9$ & $>12.0$ \\
\hline \multicolumn{6}{|c|}{ Cardiovascular system } \\
\hline & $\mathrm{MAP} \geq 70 \mathrm{mmHg}$ & $\mathrm{MAP}<70 \mathrm{mmHg}$ & $\begin{array}{l}\text { Dopamine }<5 \text { or } \\
\text { dobutamine (any dose) }{ }^{\mathrm{a}}\end{array}$ & $\begin{array}{l}\text { Dopamine } 5.1-15 \text { or } \\
\text { epinephrine } \leq 0.1 \text { or } \\
\text { norepinephrine } \leq 0 . I^{\text {a }}\end{array}$ & $\begin{array}{l}\text { Dopamine }>15 \text { or } \\
\text { epinephrine }>0.1 \text { or } \\
\text { norepinephrine }>0.1^{\mathrm{a}}\end{array}$ \\
\hline \multicolumn{6}{|l|}{ Coagulation } \\
\hline Platelets $\times 10^{3} / \mu \mathrm{L}$ & $\geq 150$ & $<150$ & $<100$ & $<50$ & $<20$ \\
\hline \multicolumn{6}{|c|}{ Central nervous system } \\
\hline Glasgow coma scale & 15 & $13-14$ & $10-12$ & $6-9$ & $<6$ \\
\hline \multicolumn{6}{|l|}{ Renal system } \\
\hline Creatinine (mg/dL) & $<\mathrm{I} .2$ & $1.2-1.9$ & $2.0-3.4$ & $3.5-4.9$ & $>5.0$ \\
\hline Urine output (mL/d) & & & & $<500$ & $<200$ \\
\hline
\end{tabular}

Notes: ${ }^{a} A l l$ catecholamine doses represent $\mu \mathrm{g} / \mathrm{kg} / \mathrm{min}$. Organ dysfunction is identified as an increase in the SOFA score of $\geq 2$ points. In patients with not known preexisting organ dysfunction, the baseline SOFA score is assumed to be zero. Intensive Care Med. The SOFA (Sepsis-related Organ Failure Assessment) score to describe organ dysfunction/failure. On behalf of the Working Group on Sepsis-Related Problems of the European Society of Intensive Care Medicine. 22(7), 1996, 707-7I0, Vincent JL, Moreno R, Takala J, et al. With permission of Springer. ${ }^{17}$

Abbreviations: $\mathrm{PaO}_{2}$, partial pressure of oxygen; $\mathrm{FiO}_{2}$, fraction of inspired oxygen; MAP, mean arterial pressure.

and management of sepsis have multiplied over past years. ${ }^{20,21}$ The "ideal biomarker," as proposed by Dupuy et al, should aid the identification of the disease [sepsis], aid direct therapy, stratify patients according to individual risk factors, and be readily available for routine clinical use. ${ }^{21} \mathrm{~A}$ single biomarker that fulfills all these requirements has not yet been identified. However, in this section, we present an overview of the latest advances in sepsis biomarkers in burn patients.

\section{Procalcitonin}

Procalcitonin (PCT) is one of the most studied biomarkers in bacterial infections and sepsis, and it is currently used clinically. ${ }^{22,23}$ This 116 -amino acid polypeptide is the prohormone of calcitonin, has a short half-life (25-30 hours), and is encoded by the $C A L C-1$ gene. Under normal conditions, PCT is produced by neuroendocrine cells, mainly in the thyroid (C-cells), where it undergoes posttranslational changes to produce calcitonin, which regulates calcium metabolism. It is also produced in low amounts in other neuroendocrine cells in the intestine and lungs. ${ }^{24-26}$ The $C A L C-1$ gene is normally suppressed in nonendocrine tissues. Bacterial infection stimulates $C A L C-1$ gene transcription in nonendocrine cells, leading to increased PCT production. ${ }^{25,27}$ PCT levels increase as early as 3 hours after bacterial infection, reaching a peak around 20 hours. After resolution of the infectious process, PCT levels decrease by $\sim 50 \%$ every day. ${ }^{23}$ The function of PCT is unclear; however, the considerable increase in PCT in relation to other indicators of bacterial infections has propelled the use of PCT as a biomarker for infection and sepsis since the 1990s. ${ }^{22,28,29} \mathrm{PCT}$ elevation is associated with bacterial infections but not with viral infections. ${ }^{28,30}$ Several studies (using a variety of patient populations, various PCT assays, and different criteria to determine sepsis) have been conducted to compare PCT to standard laboratory tests such as white blood cell (WBC) count and C-reactive protein (CRP). Although results have been mixed (CPR equivalent or superior), ${ }^{31-33}$ most of the evidence indicate that PCT is superior to CRP when used in the diagnosis of sepsis in nonburn patients. ${ }^{34-39}$ Furthermore, Brunkhorst et al showed that higher levels of PCT are associated with greater sepsis severity, and specific cutoff levels are associated with severe sepsis and septic shock in critically ill patients. ${ }^{40}$

PCT has also been studied as a tool for sepsis prognosis and diagnosis in burn patients, although not as extensively as for other critically ill populations. In a pioneer study including nine burn patients, Assicot et al were the first to report increased serum levels of PCT after burn injury and described the association of serum PCT levels with the development of infections, sepsis, and septic shock. ${ }^{22}$

Subsequent studies evaluating the value of PCT as biomarker of sepsis in burn patients have yielded inconsistent results. In 1998, von Heimburg et al studied 27 adult burn patients and found that PCT values correlated with sepsis $(r=0.84)$ and that peak but not admission PCT levels were correlated with burn size. No correlation was found between initial PCT levels (at admission) and burn size. Importantly, 
the authors concluded that the trend over time of serum PCT values was more useful than an isolated value in the diagnosis of sepsis. ${ }^{39}$

Lavrentieva et al reported that increased PCT levels were associated with sepsis in burn patients; the area under the (receiver operating characteristic) curve (AUC) was 0.98 (95\% CI $=0.9-1.0) .{ }^{41}$ Several other studies showed evidence that PCT can be used as an indicator of sepsis in burn patients. ${ }^{42-45}$ Conversely, a retrospective study by Seoane et al that included 34 episodes of suspected infection in 17 adult burn patients found no difference in PCT levels between patients with confirmed and nonconfirmed sepsis. ${ }^{46}$ In 2014, Paratz et al found no association between PCT elevation and sepsis in a prospective study including adult burn patients requiring mechanical ventilation: AUC was 0.38 (95\% CI $=0.29-0.46) .{ }^{47}$ Two additional studies failed to show the validity of PCT as a sepsis biomarker in adult and pediatric burn patients, as reflected by poor sensitivity and specificity. ${ }^{48,49}$

A recent meta-analysis of 12 heterogeneous studies of PCT as a sepsis biomarker in burn patients yielded an overall area under the summary receiver operating characteristic curve of 0.87 , a sensitivity of 0.77 , and a specificity of 0.65 . Moreover, the mean estimate between burn patients with and without sepsis was compared; the mean PCT level in patients with sepsis was $46.8 \mathrm{ng} / \mathrm{mL}(95 \% \mathrm{CI}=2.5-91.1)$ and without sepsis was $0.9 \mathrm{ng} / \mathrm{mL}(95 \% \mathrm{CI}=0.1-1.6)$. These results led Cabral et al to propose that PCT serum levels greater than $1.5 \mathrm{ng} / \mathrm{mL}$ serve as indicator of sepsis and should trigger initiation of antibiotic therapy. ${ }^{50}$

In addition, PCT levels have been used to guide deescalation and duration of antibiotic therapy. PCT-guided therapy reduces the duration of antibiotic exposure by 3.5 days in patients with respiratory infections without increasing mortality or treatment failure. ${ }^{51}$ Similarly, a metaanalysis including 14 clinical trials showed less antibiotic use in patients treated for respiratory infections in outpatient and critical care settings. ${ }^{52}$ In comparison, in septic patients, the use of PCT-based algorithms was initially associated with reduction of the duration of antibiotic therapy but not with decreased mortality or decreased length of hospital stay. ${ }^{53}$ However, more recent studies have failed to reproduce the benefit of PCT-based algorithms in the ICU setting, showing no decrease of the duration of antibiotic therapy in sepsis. ${ }^{54}$ Similarly, the results of a recent meta-analysis do not support the use of PCT-guided antimicrobial therapy to improve clinical outcomes or shorten antibiotic therapy of patients with sepsis. ${ }^{55}$
In sum, the latest evidence seems to support the use of PCT as an adjuvant in the early detection of sepsis in burn patients. However, cutoff values must be interpreted with caution and attention must be directed to evaluating the trend over time. Future large-scale studies are needed to validate the use of PCT as an indicator of prognosis and responsiveness to antimicrobial therapy in burn patients.

\section{Tumor necrosis factor alpha}

Tumor necrosis factor-alpha (TNF-alpha) is one of the most studied proinflammatory cytokines. It is produced by several cell types in response to different stressors including endotoxin, bacterial products, complement system activation, other cytokines, hypoxemia, and ischemia/reperfusion. TNF-alpha exhibits several physiological functions: activates monocytes/macrophages and natural killer (NK) cells; is implicated in the induction of apoptosis and cell survival; causes vasodilation by inducing the production of nitric oxide; promotes neutrophils chemotaxis; and activates prothrombotic and fibrinolytic pathways. ${ }^{56,57}$ Serum TNFalpha is elevated after burn patients, with higher levels observed in those who develop sepsis. ${ }^{43,58-60}$ Arslan et al found that a decrease in serum TNF-alpha level is associated with improved survival in burn patients with sepsis, pointing to the potential prognostic value of TNF-alpha in this setting. ${ }^{61}$

\section{Interleukin-6}

Interleukin-6 (IL-6) is a pleiotropic cytokine constitutively expressed in leukocytes, liver, spleen, and kidney, and it is inducible in most cell types. IL-6 has a broad range of immune functions, including modulation of the acute-phase response, induction of fever, stimulation of stress hormone production, hematopoiesis, and immune cell maturation and activation. ${ }^{62-64}$ Higher levels of IL-6 are observed in burn patients with sepsis. ${ }^{43,65}$ IL-6 has been identified as a potential prognostic marker for mortality in burn patients and is correlated with burn size. ${ }^{43,59,66}$ In a murine model of endotoxin-induced sepsis and burn injury, combined inhibition of IL-6 and the IL-6 receptor increased survival, pointing to a role for IL-6 in sepsis and sepsis-related death. ${ }^{67,68}$ In addition, Zhang et al showed, in mice, that IL-6 is involved in cardiac dysfunction accompanying burn injury complicated with sepsis. ${ }^{69}$ A recent meta-analysis was conducted to determine the utility of IL-6 as a biomarker of sepsis in trauma patients and found that IL-6 had a similar diagnostic value as PCT, with a relatively high specificity (78\%) and low sensitivity $(68 \%)$. These findings support its potential 
use as a confirmatory test rather than its use to exclude the diagnosis of sepsis. ${ }^{70}$

\section{Interleukin-8}

IL-8 is a proinflammatory cytokine produced mainly by macrophages, monocytes, and endothelial cells. IL-8 promotes migration and activation of neutrophils, inducing chemotaxis and oxidative burst. ${ }^{71,72}$ The potential utility of IL-8 as a predictor of sepsis in burn patients was first reported in 1995, when a study of 27 adult patients showed that serum IL-8 peaks after thermal injury and that a distinctive second peak is observed only in patients who develop sepsis. ${ }^{59,73,74}$ In 2008, Kraft et al studied the expression profile of 17 different cytokines in 468 pediatric patients with severe burns ( $>30 \%$ TBSA) and categorized patients into 2 groups based on IL-8 levels (cutoff value $234 \mathrm{pg} / \mathrm{mL}$ ). The authors reported that serum IL-8 values correlated with sepsis in patients with elevated IL-8 (>234 pg/mL). However, a similar association was not found in burned children who had low serum IL-8 values $(<234 \mathrm{pg} / \mathrm{mL}){ }^{75}$

\section{Interleukin- 10}

IL-10 is an anti-inflammatory cytokine that regulates the proliferation and activation of immune cells such as macrophages, B cells, Th1 cells, and NK cells. ${ }^{76}$ IL-10 inhibits the production of proinflammatory cytokines (IL-2, IL-3, IL-4, IL-2, and TNF-alpha). ${ }^{77}$ Serum IL-10 levels are elevated in sepsis; however, the "hyperactivation" of an anti-inflammatory response (ie, disproportionate production of IL-10) is thought to be linked to late mortality in sepsis ( 6 days after onset of sepsis) ${ }^{78,79}$ IL-10 serum levels increase after burn injury and progressively decline over time; however, persistent elevation might be related to infection, sepsis, or increased risk of mortality. ${ }^{80,81}$ Finnerty et al studied the cytokine profile of burned children and showed that patients with sepsis have higher levels of serum IL-10 than nonseptic patients. Nevertheless, IL-10 was not associated with mortality from sepsis in this study. ${ }^{59}$

\section{Presepsin}

Presepsin is the soluble form of cluster of differentiation 14 (CD14), a glycoprotein that functions as receptor for endotoxin complexes triggering signal transduction pathways implicated in systemic inflammation. ${ }^{82,83}$ Presepsin has been identified as an early indicator of sepsis, and serum presepsin levels have a positive association with sepsis severity. ${ }^{84-86}$ Behnes et al described the value of presepsin as a prognostic tool for mortality in critically ill patients with sepsis. ${ }^{86}$ Only one study has evaluated the utility of presepsin in identifying sepsis in burn patients. Madenci et al reported increased levels of presepsin in burn patients who developed sepsis and reported a relatively high diagnostic accuracy (AUC 0.83), similar to that of PCT in the same study (AUC 0.85). Notably, elevation of presepsin preceded elevations in PCT, WBC, and CRP by 1 day. ${ }^{87}$ Based on current evidence and as observed with other biomarkers, despite being a useful adjunct diagnostic tool, presepsin alone cannot be used to identify or rule out sepsis. ${ }^{88}$

\section{Single-nucleotide polymorphisms}

Single-nucleotide polymorphisms (SNPs), variations in a nucleotide at a specific chromosome location, have been linked to sepsis susceptibility and differences in prognosis. ${ }^{89}$ Barber et al identified specific toll-like receptor 4 and TNFalpha SNPs associated with increased risk of sepsis after burn injury. ${ }^{90}$ In a subsequent study, the same group identified IL-10 SNPs potentially associated with reduced risk of mortality. ${ }^{91}$

\section{Transcriptome}

Gene-expression patterns in circulating leukocytes after blunt trauma and thermal injury have been analyzed and compared to those in healthy subjects. The leukocyte transcriptome shifts toward increased expression of genes involved in innate immunity and the inflammatory response. ${ }^{92,93}$ These changes can persist $\sim 90$ days after burn injury. In addition, the development of infections, sepsis, and organ failure affect changes in expression of particular genes over time, as compared to an uncomplicated clinical course. ${ }^{92}$

\section{Metabolomics}

Because of the drastic metabolic changes that take place after burn injury, which are characterized by a hypercatabolic state, ${ }^{94}$ the study of the metabolic networks (ie, metabolites and involved signaling pathways) might provide potential prognostic tools in burn patients. Instead of evaluating individual parameters (metabolites), ${ }^{1} \mathrm{H}$-nuclear magnetic resonance (NMR) can be used to assess systemic changes in metabolically active molecules and paired with mathematical modeling to study a metabolic profile or metabolome..$^{95,96}$ Zhang et al used NMR integrated with network analysis to show complex metabolic alterations in burn patients and crated a quantitative injury severity scoring system. ${ }^{97}$ However, the use of metabolome analysis as a prognostic tool to predict sepsis or survival in burn patients has not yet been validated. 


\section{Management of sepsis in burn patients}

The Surviving Sepsis Campaign provides general treatment guidelines and recommendations, most of which are applicable to burn patients. ${ }^{98}$ After the presumptive diagnosis of sepsis has been established, biological samples should be collected for microbiological studies and fluid resuscitation should be started immediately, along with timely (within 1 hour) initiation of antimicrobial therapy followed by source control when feasible. Although controversy exists as to whether any survival benefit is derived from the "one hour rule," $12,13,99$ adhering to the principle of early initiation of antibiotic therapy is reasonable, considering that the vast majority of burn patients who develop sepsis are hospitalized.

\section{Resuscitation}

Burn patients receive large amounts of fluid as part of the initial fluid resuscitation immediately after thermal injury. After resuscitation and stabilization, thorough clinical examination and monitoring of physiologic variables must be performed regularly to tailor therapeutic interventions that favor euvolemia (ie, judicious use of fluids and administration of diuretics when necessary). ${ }^{100}$ Sepsis and septic shock are medical emergencies; patients are usually intravascularly depleted and require fluid administration. In nonburn patients, an initial administration of at least $30 \mathrm{~mL} / \mathrm{kg}$ of intravenous crystalloids is recommended to treat sepsis-induced hypoperfusion, followed by additional fluids as required, based on hemodynamic status. ${ }^{98}$ Methods used to monitor burn resuscitation can also be used to guide resuscitation in sepsis management of burn patients. These methods have been recently reviewed. ${ }^{101}$ The volume and type of fluids administered to septic burn patients will be dictated by several factors including patient age, fluid creep (excessive fluid administration during acute burn resuscitation), ${ }^{102}$ cardiac and renal function, and increased insensible water loss due to noncovered burn wounds. Ideally, a mean arterial pressure (MAP) $\geq 65 \mathrm{mmHg}$ and a normalized level of lactate are the targets of fluid resuscitation, as both hypotension and hyperlactatemia are indicators of tissue hypoperfusion. ${ }^{98,103}$

\section{Antimicrobial therapy}

Appropriate intravenous antimicrobial therapy should preferably be started within 1 hour. However, no standard regimen that is suitable for all burn patients with sepsis can be recommended. Antibiotic selection must be individualized and include one or more broad-spectrum antibiotics that cover the most likely pathogens, based on data from the local antibiogram. Most cases of sepsis in burn patients are secondary to infected burn wounds; Pseudomonas aeruginosa and methicillin-resistant Staphylococcus aureus are the most common isolated organisms causing infection in burn patients. ${ }^{104-106}$ However, several variables that must be considered when selecting an antibiotic regimen include epidemiologic factors (patients transferred from other facilities with different pathogens and resistance patterns); patient history (preexisting diseases, recent infections, prior use of antibiotics, immunosuppressed status, drug allergies); and clinical presentation. Septic shock should be treated with at least two antibiotics of different classes; the anatomic site of infection can provide clues as to pathogen type and antibiotic penetration..$^{98}$ Timely initiation and appropriate choice of antibiotics increase the chances of survival, while inadequate antimicrobial treatment has been associated with increased mortality. ${ }^{107-109}$

Modifications in the dose of antimicrobials might be necessary to ensure a therapeutic effect and avoid drug toxicity. These modifications might be dictated by patient characteristics such as preexisting kidney disease or deterioration of kidney function, or they might be needed owing to drug pharmacokinetics. For instance, vancomycin levels should be monitored daily to maintain levels within the therapeutic range $(10-15 \mu \mathrm{g} / \mathrm{mL}) .{ }^{104}$ Special attention must be paid to the combination of antibiotics used; some combinations may increase toxicity. For example, vancomycin and piperacillin/ tazobactam pose a higher risk of nephrotoxicity than vancomycin and meropenem or vancomycin and cefepime. ${ }^{110,111}$

Once pathogen identification and sensitivities are known, antibiotic de-escalation is recommended, that is, replace broad-spectrum antibiotics with narrow-spectrum antibiotics, decrease the number of antibiotics, or terminate antibiotic therapy early. However, this practice is currently controversial, as the benefit of decreased mortality found in observational studies has not been consistently replicated in clinical trials or meta-analyses. ${ }^{112-114}$ Despite the lack of evidence indicating decreased mortality, antibiotic de-escalation is safe and can be implemented in the management of septic burn patients when supported by both microbiological data and clinical judgement. ${ }^{115}$

The appearance of new multidrug-resistant organisms (MDROs) is an increasing problem in burn centers across the world. ${ }^{104,116,117}$ Colistin, an old antibiotic discontinued because of its nephrotoxicity, has re-emerged as an useful agent in the treatment of infections caused by MDRO. ${ }^{118,119}$ However, due to the use of colistin, the appearance of colistin-resistant organisms is worrisome, as available therapeutic options 
seem scarce; some studies have reported the usefulness of combination therapy (eg, colistin, amikacin, tigecycline) in the treatment of colistin-resistant infections. ${ }^{120,121}$ Early consultation of infectious diseases specialists is advocated in challenging cases. A duration of at least 7 days of systemic antibiotics is recommended. Longer treatment courses must be indicated based on clinical response. ${ }^{98}$ The effectiveness of a short-duration course of antimicrobial therapy has been demonstrated in a broad spectrum of severe infections. ${ }^{122-124}$

The management of sepsis secondary to fungal or viral infections follows the same principles, and systemic antifungals or antivirals must be administered, respectively. Bacterial coinfection is common in these circumstances. Therefore, antibiotic coverage is also recommended. Sepsis secondary to fungal infection is suspected when a favorable response is not observed after appropriate broad-spectrum antibiotic coverage. Burn patients have several risk factors for fungal infections including open wounds, immunocompromised status, indwelling catheters, serial surgical procedures, the use of hydrotherapy, prolonged administration of antibiotics, and prolonged hospitalizations. ${ }^{125,126}$ Central venous catheters should be removed once fungemia is identified. The choice of antifungal agent must be tailored to cover the most prevalent pathogens in the local burn unit. Empirically, triazoles can be used in stable patients, while liposomal amphotericin B or echinocandins are preferred in the presence of hemodynamic compromise, severe infections, or prior exposure to triazoles. Local resistance pattern data and susceptibility results are valuable tools to guide antifungal selection. The duration of antifungal treatment is variable. In general, burn patients with fungemia are treated for at least 2 weeks after obtaining negative blood cultures. Invasive fungal infections require aggressive surgical treatment to limit the propagation of the infection and a longer duration of antifungal therapy and consultation with an infectious diseases specialist is recommended.

\section{Vasoactive medications}

Vasopressor therapy is recommended in patients who fail to reach resuscitation targets despite fluid administration. Norepinephrine is the first vasopressor that should be used. If another vasopressor needs to be added, either vasopressin or epinephrine can be considered; ${ }^{127}$ dopamine can be used in patients with a low risk of cardiac arrhythmias and preferably after reaching euvolemia. ${ }^{128}$ Continuous hemodynamic monitoring is mandatory for patients receiving vasoactive medications, which should be titrated to achieve tissue perfusion using the lowest dose possible. ${ }^{98}$ If hypotension is refractory (ie, systolic blood pressure $<90 \mathrm{mmHg}$ persists for more than 1 hour despite fluid resuscitation and vasopressors), adrenal insufficiency must be considered. In these cases, a low dose of hydrocortisone should be administered. Low-dose hydrocortisone has been linked to decreased mortality in septic shock patients in some clinical trials, while other studies have shown no survival benefit. A recent randomized clinical trial in severely burn patients showed that low-dose hydrocortisone decreases norepinephrine requirements during initial resuscitation following burns. ${ }^{78}$ A similar study in burn patients with septic shock has not yet been performed. Therefore, hydrocortisone can be used in patients with refractory hypotension, though the survival benefit remains to be proven.

\section{Source control}

After fluid resuscitation, hemodynamic stabilization, and initiation of systemic antibiotic therapy, control of the source of infection should be performed in a timely manner. Although the window of time necessary to achieve source control to ensure favorable outcomes varies, 6-12 hours after diagnosis is a reasonable time. ${ }^{98,129,130}$ Infected burn wounds are the most common source of sepsis in burn patients. Burn wound infection usually presents with cellulitis of surrounding tissues, changes in coloration of the wound, discolored exudates, or characteristic odors. More severe cases or invasive burn wound infections are characterized by the progression of a partial-thickness burn to full-thickness necrosis. ${ }^{131}$ Source control of infected burn wounds is achieved by debridement of infected and necrotic areas until healthy viable tissue is found. Debridement must be followed by a thorough inspection within 24-48 hours. If necrotic tissue is again identified, the affected areas must be excised; wound coverage can be performed if the wound appears healthy. ${ }^{131,132}$

Infection sources other than burn wounds require an individualized approach, with the principles of the management being the same as those for nonburn patients. ${ }^{98}$ Intravascular devices (arterial lines or central venous catheters) suspected to be the source of infection should be removed, after obtaining intravenous access using a different anatomic site. Abscesses (soft tissue or abdominal abscesses) are drained using the most favorable method (surgical debridement, open drainage, percutaneous drainage) based on clinical conditions as well as on the location, number, and size of abscesses. Abdominal catastrophes (bowel ischemia, intestinal perforation with peritonitis, volvulus) generally 
will require surgical exploration. ${ }^{133}$ The intervention needed to achieve control must be individualized and executed in a timely manner. Hemodynamic stabilization with medical therapies is desired before proceeding with source control. However, in some cases of septic shock, stabilization is not obtainable until source control has been achieved. In these circumstances, delaying source control due to prolonged medical stabilization is not desirable. ${ }^{134}$

\section{Conclusion}

Sepsis and septic shock represent medical emergencies commonly encountered during the care of burn patients. The diagnosis of sepsis after severe burn injury is challenging owing to the overlap of signs and clinical manifestations of the hypermetabolic response thermal injury and sepsis. The definition of sepsis and the diagnostic criteria have evolved due to improved understanding of the underlying pathophysiology. Despite significant research efforts, a biomarker with significant prognostic or diagnostic value has yet to be incorporated into routine clinical practice in burn patients. The combination of both clinical information and biomarker values continues to be the best option for early identification of septic patients. Implementation of general basic principles along with individualization of treatment is important in the management of sepsis, with an emphasis of timely delivery of treatment to increase the odds of a favorable prognosis.

\section{Acknowledgment}

The authors thank Drs Kasie Cole-Edwards and Victoria Rontoyanni for their critical review and editorial assistance.

\section{Disclosure}

The authors report no conflicts of interest in this work.

\section{References}

1. American Burn Association. National Burn Repository 2016. Chicago, IL; 2016. Available from: http://ameriburn.org/education/publications/.

2. Williams FN, Herndon DN, Hawkins HK, et al. The leading causes of death after burn injury in a single pediatric burn center. Crit Care. 2009; 13(6):R183.

3. Dasari H, Kumar A, Sharma B. Burns septicemia: the leading cause of burn mortality. J Punjab Acad Forensic Med Toxicol. 2008;8(2): $10-16$.

4. Sharma BR, Harish D, Singh VP, Bangar S. Septicemia as a cause of death in burns: an autopsy study. Burns. 2006;32(5):545-549.

5. D'Avignon LC, Hogan BK, Murray CK, et al. Contribution of bacterial and viral infections to attributable mortality in patients with severe burns: an autopsy series. Burns. 2010;36(6):773-779.

6. O'Sullivan ST, O'Connor TP. Immunosuppression following thermal injury: the pathogenesis of immunodysfunction. Br J Plast Surg. 1997; 50(8):615-623.

7. Schwacha MG. Macrophages and post-burn immune dysfunction. Burns. 2003;29(1):1-14.
8. Girardot T, Rimmele T, Venet F, Monneret G. Apoptosis-induced lymphopenia in sepsis and other severe injuries. Apoptosis. 2017;22(2): 295-305.

9. Singer M, Deutschman CS, Seymour CW, et al. The third international consensus definitions for sepsis and septic shock (sepsis-3). JAMA. 2016;315(8):801-810.

10. Greenhalgh DG, Saffle JR, Holmes JH 4th, et al. American Burn Association consensus conference to define sepsis and infection in burns. J Burn Care Res. 2007;28(6):776-790.

11. Howell MD, Davis AM. Management of sepsis and septic shock. JAMA. 2017;317(8):847-848.

12. Ferrer R, Martin-Loeches I, Phillips G, et al. Empiric antibiotic treatment reduces mortality in severe sepsis and septic shock from the first hour: results from a guideline-based performance improvement program. Crit Care Med. 2014;42(8):1749-1755.

13. Sterling SA, Miller WR, Pryor J, Puskarich MA, Jones AE. The impact of timing of antibiotics on outcomes in severe sepsis and septic shock: a systematic review and meta-analysis. Crit Care Med. 2015; 43(9):1907-1915.

14. Kumar A, Roberts D, Wood KE, et al. Duration of hypotension before initiation of effective antimicrobial therapy is the critical determinant of survival in human septic shock. Crit Care Med. 2006; 34(6):1589-1596.

15. Bone RC, Balk RA, Cerra FB, et al. Definitions for sepsis and organ failure and guidelines for the use of innovative therapies in sepsis. The ACCP/SCCM Consensus Conference Committee. American College of Chest Physicians/Society of Critical Care Medicine. Chest. 1992;101(6):1644-1655.

16. Levy MM, Fink MP, Marshall JC, et al. 2001 SCCM/ESICM/ACCP/ ATS/SIS International Sepsis Definitions Conference. Intensive Care Med. 2003;29(4):530-538.

17. Vincent JL, Moreno R, Takala J, et al. The SOFA (Sepsis-related Organ Failure Assessment) score to describe organ dysfunction/failure. On behalf of the Working Group on Sepsis-Related Problems of the European Society of Intensive Care Medicine. Intensive Care Med. 1996;22(7):707-710.

18. Seymour CW, Liu VX, Iwashyna TJ, et al. Assessment of clinical criteria for sepsis: For the third international consensus definitions for sepsis and septic shock (sepsis-3). JAMA. 2016;315(8):762-774.

19. Freund Y, Lemachatti N, Krastinova E, et al. Prognostic accuracy of sepsis-3 criteria for in-hospital mortality among patients with suspected infection presenting to the emergency department. JAMA. 2017;317(3):301-308.

20. Hedegaard SS, Wisborg K, Hvas A-M. Diagnostic utility of biomarkers for neonatal sepsis - a systematic review. Infect Dis (London, England). 2015;47(3):117-124.

21. Dupuy A-M, Philippart F, Pean Y, et al. Role of biomarkers in the management of antibiotic therapy: an expert panel review: I - currently available biomarkers for clinical use in acute infections. Ann Intensive Care. 2013;3(1):22.

22. Assicot M, Gendrel D, Carsin H, Raymond J, Guilbaud J, Bohuon C. High serum procalcitonin concentrations in patients with sepsis and infection. Lancet (London, England). 1993;341(8844):515-518.

23. Long B, Koyfman A. Ready for prime time? Biomarkers in sepsis. Emerg Med Clin North Am. 2017;35(1):109-122.

24. Meisner M. Pathobiochemistry and clinical use of procalcitonin. Clin Chim Acta. 2002;323:17-29.

25. Schneider HG, Lam QT. Procalcitonin for the clinical laboratory: a review. Pathology. 2007;39:383-390.

26. Jin M, Khan AI. Procalcitonin: uses in the clinical laboratory for the diagnosis of sepsis. Lab Med. 2010;41(3):173-177.

27. Becker KL, Nylen ES, White JC, Muller B, Snider RHJ. Procalcitonin and the calcitonin gene family of peptides in inflammation, infection, and sepsis: a journey from calcitonin back to its precursors. $J$ Clin Endocrinol Metab. 2004;89(4):1512-1525.

28. Gendrel D, Assicot M, Raymond J, et al. Procalcitonin as a marker for the early diagnosis of neonatal infection. J Pediatr. 1996;128(4): 570-573. 
29. Schlattmann P, Brunkhorst FM. Procalcitonin as a diagnostic marker for sepsis. Lancet Infect Dis. 2014;14(3):189.

30. Yang M, Gao H, Chen J, et al. Bacterial coinfection is associated with severity of avian influenza A (H7N9), and procalcitonin is a usefu marker for early diagnosis. Diagn Microbiol Infect Dis. 2016;84(2): $165-169$.

31. Ugarte H, Silva E, Mercan D, De Mendonca A, Vincent JL. Procalcitonin used as a marker of infection in the intensive care unit. Crit Care Med. 1999;27(3):498-504.

32. Bell K, Wattie M, Byth K, et al. Procalcitonin: a marker of bacteraemia in SIRS. Anaesth Intensive Care. 2003;31(6):629-636.

33. Suprin E, Camus C, Gacouin A, et al. Procalcitonin: a valuable indicator of infection in a medical ICU? Intensive Care Med. 2000;26(9): 1232-1238.

34. Brunkhorst FM, Eberhard OK, Brunkhorst R. Discrimination of infectious and noninfectious causes of early acute respiratory distress syndrome by procalcitonin. Crit Care Med. 1999;27(10):2172-2176.

35. Simon L, Gauvin F, Amre DK. Serum procalcitonin and C-reactive protein levels as markers of bacterial infection: a systematic review and meta-analysis. Clin Infect Dis. 2004;39:206-217.

36. Uzzan B, Cohen R, Nicolas P, Cucherat M, Perret G-Y. Procalcitonin as a diagnostic test for sepsis in critically ill adults and after surgery or trauma: a systematic review and meta-analysis. Crit Care Med. 2006;34(7):1996-2003.

37. Clec'h C, Ferriere F, Karoubi P, et al. Diagnostic and prognostic value of procalcitonin in patients with septic shock. Crit Care Med. 2004;32(5):1166-1169.

38. Wacker C, Prkno A, Brunkhorst FM, Schlattmann P. Procalcitonin as a diagnostic marker for sepsis: a systematic review and meta-analysis Lancet Infect Dis. 2013;13(5):426-435.

39. von Heimburg D, Stieghorst W, Khorram-Sefat R, Pallua N. Procalcitonin - a sepsis parameter in severe burn injuries. Burns. 1998; 24(8):745-750.

40. Brunkhorst FM, Wegscheider K, Forycki ZF, Brunkhorst R. Procalcitonin for early diagnosis and differentiation of SIRS, sepsis, severe sepsis, and septic shock. Intensive Care Med. 2000;26(Suppl 2):S148-S152.

41. Lavrentieva A, Kontakiotis T, Lazaridis L, et al. Inflammatory markers in patients with severe burn injury: what is the best indicator of sepsis? Burns. 2007;33(2):189-194.

42. Sachse C, Machens HG, Felmerer G, Berger A, Henkel E. Procalcitonin as a marker for the early diagnosis of severe infection after thermal injury. J Burn Care Rehabil. 1999;20(5):354-360.

43. Abdel-Hafez NM, Saleh Hassan Y, El-Metwally TH. A study on biomarkers, cytokines, and growth factors in children with burn injuries Ann Burns Fire Disasters. 2007;20(2):89-100.

44. Barati M, Alinejad F, Bahar MA, et al. Comparison of WBC, ESR, CRP and PCT serum levels in septic and non-septic burn cases. Burns. 2008;34(6):770-774.

45. Gille J, Ostermann H, Dragu A, Sablotzki A. MR-proADM: a new biomarker for early diagnosis of sepsis in burned patients. J Burn Care Res. Epub Mar 28, 2017.

46. Seoane L, Pertega S, Galeiras R, Astola I, Bouza T. Procalcitonin in the burn unit and the diagnosis of infection. Burns. 2014;40(2):223-229.

47. Paratz JD, Lipman J, Boots RJ, Muller MJ, Paterson DL. A new marker of sepsis post burn injury? Crit Care Med. 2014;42(9):2029-2036.

48. Neely AN, Fowler LA, Kagan RJ, Warden GD. Procalcitonin in pediatric burn patients: an early indicator of sepsis? J Burn Care Rehabil. 2004;25(1):76-80.

49. Bargues L, Chancerelle Y, Catineau J, Jault P, Carsin H. Evaluation of serum procalcitonin concentration in the ICU following severe burn. Burns. 2007;33(7):860-864

50. Cabral L, Afreixo V, Almeida L, Paiva JA. The use of procalcitonin (PCT) for diagnosis of sepsis in burn patients: a meta-analysis PLoS One. 2016;11(12):e0168475.

51. Schuetz P, Briel M, Christ-Crain M, et al. Procalcitonin to guide initiation and duration of antibiotic treatment in acute respiratory infections: an individual patient data meta-analysis. Clin Infect Dis An Off Publ Infect Dis Soc Am. 2012;55(5):651-662.
52. Schuetz P, Briel M, Mueller B. Clinical outcomes associated with procalcitonin algorithms to guide antibiotic therapy in respiratory tract infections. JAMA. 2013;309(7):717-718.

53. Prkno A, Wacker C, Brunkhorst FM, Schlattmann P. Procalcitoninguided therapy in intensive care unit patients with severe sepsis and septic shock - a systematic review and meta-analysis. Crit Care. 2013; 17(6):R291

54. Chu DC, Mehta AB, Walkey AJ. Practice patterns and outcomes associated with procalcitonin use in critically ill patients with sepsis. Clin Infect Dis. 2017;64(11):1509-1515.

55. Andriolo BN, Andriolo RB, Salomao R, Atallah AN. Effectiveness and safety of procalcitonin evaluation for reducing mortality in adults with sepsis, severe sepsis or septic shock. Cochrane Database Syst Rev. 2017;1:CD010959.

56. Surbatovic M, Veljovic M, Jevdjic J, Popovic N, Djordjevic D, Radakovic S. Immunoinflammatory response in critically ill patients: severe sepsis and/or trauma. Mediators Inflamm. 2013;2013:362793.

57. Parameswaran N, Patial S. Tumor necrosis factor-alpha signaling in macrophages. Crit Rev Eukaryot Gene Expr. 2010;20(2):87-103.

58. Yamada Y, Endo S, Inada K. Plasma cytokine levels in patients with severe burn injury - with reference to the relationship between infection and prognosis. Burns. 1996;22(8):587-593.

59. Finnerty CC, Herndon DN, Chinkes DL, Jeschke MG. Serum cytokine differences in severely burned children with and without sepsis. Shock. 2007;27(1):4-9.

60. Drost AC, Burleson DG, Cioffi WGJ, Mason ADJ, Pruitt BAJ. Plasma cytokines after thermal injury and their relationship to infection. Ann Surg. 1993;218(1):74-78.

61. Arslan E, Yavuz M, Dalay C. The relationship between tumor necrosis factor (TNF)-alpha and survival following granulocyte-colony stimulating factor (G-CSF) administration in burn sepsis. Burns. 2000;26(6):521-524.

62. Jawa RS, Anillo S, Huntoon K, Baumann H, Kulaylat M. Analytic review: interleukin-6 in surgery, trauma, and critical care: part I: basic science. J Intensive Care Med. 2011;26(1):3-12.

63. Jawa RS, Anillo S, Huntoon K, Baumann H, Kulaylat M. Interleukin-6 in surgery, trauma, and critical care part II: clinical implications. J Intensive Care Med. 2011;26(2):73-87.

64. Schluter B, Konig B, Bergmann U, Muller FE, Konig W. Interleukin 6-a potential mediator of lethal sepsis after major thermal trauma: evidence for increased IL-6 production by peripheral blood mononuclear cells. J Trauma. 1991;31(12):1663-1670.

65. Finnerty CC, Herndon DN, Przkora R, et al. Cytokine expression profile over time in severely burned pediatric patients. Shock. 2006; 26(1):13-19.

66. Carsin H, Assicot M, Feger F, et al. Evolution and significance of circulating procalcitonin levels compared with IL-6, TNF alpha and endotoxin levels early after thermal injury. Burns. 1997;23(3): 218-224.

67. Pallua N, von Heimburg D. Pathogenic role of interleukin-6 in the development of sepsis. Part I: study in a standardized contact burn murine model. Crit Care Med. 2003;31(5):1490-1494.

68. Pallua N, Low JFA, von Heimburg D. Pathogenic role of interleukin- 6 in the development of sepsis. Part II: significance of anti-interleukin-6 and anti-soluble interleukin-6 receptor-alpha antibodies in a standardized murine contact burn model. Crit Care Med. 2003;31(5):1495-1501.

69. Zhang H, Wang H-Y, Bassel-Duby R, et al. Role of interleukin-6 in cardiac inflammation and dysfunction after burn complicated by sepsis. Am J Physiol Heart Circ Physiol. 2007;292(5):H2408-H2416.

70. Ma L, Zhang H, Yin Y, et al. Role of interleukin-6 to differentiate sepsis from non-infectious systemic inflammatory response syndrome. Cytokine. 2016;88:126-135.

71. Baggiolini M, Walz A, Kunkel SL. Neutrophil-activating peptide-1/ interleukin 8, a novel cytokine that activates neutrophils. J Clin Invest. 1989;84(4):1045-1049.

72. Baggiolini M, Clark-Lewis I. Interleukin-8, a chemotactic and inflammatory cytokine. FEBS Lett. 1992;307(1):97-101. 
73. Vindenes H, Ulvestad E, Bjerknes R. Increased levels of circulating interleukin- 8 in patients with large burns: relation to burn size and sepsis. J Trauma. 1995;39(4):635-640.

74. Yeh FL, Lin WL, Shen HD, Fang RH. Changes in levels of serum IL-8 in burned patients. Burns. 1997;23(7-8):555-559.

75. Kraft R, Herndon DN, Finnerty CC, Cox RA, Song J, Jeschke MG. Predictive value of IL-8 for sepsis and severe infections after burn injury: a clinical study. Shock. 2015;43(3):222-227.

76. Asadullah K, Sterry W, Volk HD. Interleukin-10 therapy-review of a new approach. Pharmacol Rev. 2003;55(2):241-269.

77. Kumar S, Shukla R, Ranjan P, Kumar A. Interleukin-10: a compelling therapeutic target in patients with irritable bowel syndrome. Clin Ther. 2017;39(3):632-643.

78. Monneret G, Finck M-E, Venet F, et al. The anti-inflammatory response dominates after septic shock: association of low monocyte HLA-DR expression and high interleukin-10 concentration. Immunol Lett. 2004;95(2):193-198.

79. Hotchkiss RS, Monneret G, Payen D. Sepsis-induced immunosuppression: from cellular dysfunctions to immunotherapy. Nat Rev Immunol. 2013;13(12):862-874.

80. Csontos C, Foldi V, Palinkas L, et al. Time course of pro- and antiinflammatory cytokine levels in patients with burns - prognostic value of interleukin-10. Burns. 2010;36(4):483-494.

81. Pileri D, Accardo Palombo A, D'Amelio L, et al. Concentrations of cytokines Il-6 and Il-10 in plasma of burn patients: their relationship to sepsis and outcome. Ann Burns Fire Disasters. 2008;21(4):182-185.

82. Yaegashi Y, Sato N, Suzuki Y, et al. Evaluation of a newly identified soluble CD14 subtype as a marker for sepsis. $J$ Infect Chemother. 2005;11(5):234-238.

83. Wu J, Hu L, Zhang G, Wu F, He T. Accuracy of presepsin in sepsis diagnosis: a systematic review and meta-analysis. PLoS One. 2015;10(7):e0133057.

84. Shozushima T, Takahashi G, Matsumoto N, Kojika M, Endo S, Okamura Y. Usefulness of presepsin (sCD14-ST) measurements as a marker for the diagnosis and severity of sepsis that satisfied diagnostic criteria of systemic inflammatory response syndrome. $J$ Infect Chemother. 2011;17(6):764-769.

85. Mussap M, Noto A, Fravega M, Fanos V. Soluble CD14 subtype presepsin (sCD14-ST) and lipopolysaccharide binding protein (LBP) in neonatal sepsis: new clinical and analytical perspectives for two old biomarkers. J Matern Fetal Neonatal Med. 2011;24(Suppl 2):12-14.

86. Behnes M, Bertsch T, Lepiorz D, et al. Diagnostic and prognostic utility of soluble CD 14 subtype (presepsin) for severe sepsis and septic shock during the first week of intensive care treatment. Crit Care. 2014;18(5):507.

87. Cakir Madenci O, Yakupoglu S, Benzonana N, Yucel N, Akbaba D, Orcun Kaptanagasi A. Evaluation of soluble CD14 subtype (presepsin) in burn sepsis. Burns. 2014;40(4):664-669.

88. Zhang J, Hu Z-D, Song J, Shao J. Diagnostic value of presepsin for sepsis: a systematic review and meta-analysis. Medicine (Baltimore). 2015;94(47):e2158.

89. Liu X, Ren H, Peng D. Sepsis biomarkers: an omics perspective. Front Med. 2014;8(1):58-67.

90. Barber R, Aragaki C, Rivera-Chavez F, Purdue G, Hunt J, Horton J. TLR4 and TNF- $\alpha$ polymorphisms are associated with an increased risk for severe sepsis following burn injury. J Med Genet. 2004;41(11): $808-813$.

91. Huebinger RM, Rivera-Chavez F, Chang L-Y, et al. IL-10 polymorphism associated with decreased risk for mortality after burn injury. J Surg Res. 2010;164(1):e141-e145.

92. Xiao W, Mindrinos MN, Seok J, et al. A genomic storm in critically injured humans. J Exp Med. 2011;208(13):2581-2590.

93. Bauer M, Giamarellos-Bourboulis EJ, Kortgen A, et al. A transcriptomic biomarker to quantify systemic inflammation in sepsis - a prospective multicenter Phase II diagnostic study. EBioMedicine. 2016;6:114-125.

94. Porter C, Tompkins RG, Finnerty CC, Sidossis LS, Suman OE, Herndon DN. The metabolic stress response to burn trauma: current understanding and therapies. Lancet. 2017;388(10052):1417-1426.
95. Jiang H, Peng J, Zhou Z, et al. Establishing (1)H nuclear magnetic resonance based metabonomics fingerprinting profile for spinal cord injury: a pilot study. Chin Med J (Engl). 2010;123(17):2315-2319.

96. Peng J, Zeng J, Cai B, et al. Establishment of quantitative severity evaluation model for spinal cord injury by metabolomic fingerprinting. PLoS One. 2014;9(4):e93736.

97. Zhang Y, Cai B, Jiang H, et al. Use of (1)H-nuclear magnetic resonance to screen a set of biomarkers for monitoring metabolic disturbances in severe burn patients. Crit Care. 2014;18(4):R159.

98. Rhodes A, Evans LE, Alhazzani W, et al. Surviving Sepsis Campaign: International Guidelines for Management of Sepsis and Septic Shock: 2016. Intensive Care Med. 2017;43(3):304-377.

99. Shirakura Y, Kuriyama A. Timing of antibiotic administration in sepsis and septic shock: the impact that a meta-analysis does not depict. Crit Care Med. 2016;44(10):e1004.

100. White CE, Renz EM. Advances in surgical care: management of severe burn injury. Crit Care Med. 2008;36(7 Suppl):S318-S324.

101. Caruso DM, Matthews MR. Monitoring end points of burn resuscitation. Crit Care Clin. 2016;32(4):525-537.

102. Pruitt BAJ. Protection from excessive resuscitation: "pushing the pendulum back". J Trauma. 2000;49(3):567-568.

103. LeDoux D, Astiz ME, Carpati CM, Rackow EC. Effects of perfusion pressure on tissue perfusion in septic shock. Crit Care Med. 2000;28(8):2729-2732.

104. Norbury W, Herndon DN, Tanksley J, Jeschke MG, Finnerty CC. Infection in burns. Surg Infect (Larchmt). 2016;17(2):250-255.

105. Bahemia IA, Muganza A, Moore R, Sahid F, Menezes CN. Microbiology and antibiotic resistance in severe burns patients: a 5 year review in an adult burns unit. Burns. 2015;41(7):1536-1542.

106. Fekih Hassen A, Ben Khalifa S, Daiki M. Epidemiological and bacteriological profiles in children with burns. Burns. 2014;40(5): 1040-1045.

107. Barie PS, Hydo LJ, Shou J, Larone DH, Eachempati SR. Influence of antibiotic therapy on mortality of critical surgical illness caused or complicated by infection. Surg Infect (Larchmt). 2005;6(1):41-54.

108. Kumar A, Ellis P, Arabi Y, et al. Initiation of inappropriate antimicrobial therapy results in a fivefold reduction of survival in human septic shock. Chest. 2009;136(5):1237-1248.

109. Ibrahim EH, Sherman G, Ward S, Fraser VJ, Kollef MH. The influence of inadequate antimicrobial treatment of bloodstream infections on patient outcomes in the ICU setting. Chest. 2000;118(1): 146-155.

110. Peyko V, Smalley S, Cohen H. Prospective comparison of acute kidney injury during treatment with the combination of piperacillintazobactam and vancomycin versus the combination of cefepime or meropenem and vancomycin. J Pharm Pract. 2017;30(2):209-213.

111. Gomes DM, Smotherman C, Birch A, et al. Comparison of acute kidney injury during treatment with vancomycin in combination with piperacillin-tazobactam or cefepime. Pharmacotherapy. 2014; 34(7):662-669.

112. De Bus L, Denys W, Catteeuw J, et al. Impact of de-escalation of beta-lactam antibiotics on the emergence of antibiotic resistance in ICU patients: a retrospective observational study. Intensive Care Med. 2016;42(6):1029-1039.

113. Alshukairi A, Alserehi H, El-Saed A, et al. A de-escalation protocol for febrile neutropenia cases and its impact on carbapenem resistance: a retrospective, quasi-experimental single-center study. J Infect Public Health. 2016;9(4):443-451.

114. Garnacho-Montero J, Gutierrez-Pizarraya A, Escoresca-Ortega A, et al. De-escalation of empirical therapy is associated with lower mortality in patients with severe sepsis and septic shock. Intensive Care Med. 2014;40(1):32-40.

115. Guo Y, Gao W, Yang H, Ma C, Sui S. De-escalation of empiric antibiotics in patients with severe sepsis or septic shock: a meta-analysis. Heart Lung. 2016;45(5):454-459.

116. Singh NP, Rani M, Gupta K, Sagar T, Kaur IR. Changing trends in antimicrobial susceptibility pattern of bacterial isolates in a burn unit. Burns. 2017;43(5):1083-1087. 
117. Keen EF 3rd, Robinson BJ, Hospenthal DR, et al. Prevalence of multidrug-resistant organisms recovered at a military burn center. Burns. 2010;36(6):819-825.

118. Adibhesami H, Douraghi M, Zeraati H, et al. Carbapenemresistant Acinetobacter baumannii (CRAB) recovered from burn patients. J Pharm Pharm Sci. 2016;19(3):339-348.

119. De Vos D, Pirnay J-P, Bilocq F, et al. Molecular epidemiology and clinical impact of Acinetobacter calcoaceticus-baumannii complex in a Belgian burn wound center. PLoS One. 2016;11(5):e0156237.

120. de Maio Carrillho CMD, Gaudereto JJ, Martins RCR, et al. Colistinresistant Enterobacteriaceae infections: clinical and molecular characterization and analysis of in vitro synergy. Diagn Microbiol Infect Dis. 2017;87(3):253-257.

121. Viaggi B, Sbrana F, Malacarne P, Tascini C. Ventilator-associated pneumonia caused by colistin-resistant KPC-producing Klebsiella pneumoniae: a case report and literature review. Respir Investig. 2015;53(3):124-128.

122. Rattan R, Allen CJ, Sawyer RG, et al. Patients with complicated intra-abdominal infection presenting with sepsis do not require longer duration of antimicrobial therapy. J Am Coll Surg. 2016;222(4): 440-446.

123. Chastre J, Wolff M, Fagon J-Y, et al. Comparison of 8 vs 15 days of antibiotic therapy for ventilator-associated pneumonia in adults: a randomized trial. JAMA. 2003;290(19):2588-2598.

124. Choudhury G, Mandal P, Singanayagam A, Akram AR, Chalmers JD, Hill AT. Seven-day antibiotic courses have similar efficacy to prolonged courses in severe community-acquired pneumonia - a propensityadjusted analysis. Clin Microbiol Infect. 2011;17(12):1852-1858.

125. Struck MF, Gille J. Fungal infections in burns: a comprehensive review. Ann Burns Fire Disasters. 2013;26(3):147-153.
126. Ballard J, Edelman L, Saffle J, et al. Positive fungal cultures in burn patients: a multicenter review. J Burn Care Res. 2008;29(1): 213-221.

127. Russell JA, Walley KR, Singer J, et al. Vasopressin versus norepinephrine infusion in patients with septic shock. $N$ Engl J Med. 2008; 358(9):877-887.

128. Lundy JB, Chung KK, Pamplin JC, Ainsworth CR, Jeng JC, Friedman BC. Update on severe burn management for the Intensivist. J Intensive Care Med. 2016;31(8):499-510.

129. Wong C-H, Chang H-C, Pasupathy S, Khin L-W, Tan J-L, Low C-O. Necrotizing fasciitis: clinical presentation, microbiology, and determinants of mortality. J Bone Joint Surg Am. 2003;85-A(8): 1454-1460.

130. Azuhata T, Kinoshita K, Kawano D, et al. Time from admission to initiation of surgery for source control is a critical determinant of survival in patients with gastrointestinal perforation with associated septic shock. Crit Care. 2014;18(3):R87.

131. Gallagher JJ, Branski LK, Williams-Bouyer N, Villarreal C, Herndon DN. Chapter 12 - Treatment of infection in burns BT-total burn care. 4th ed. London: W.B. Saunders; 2012:137-156.e2.

132. Pruitt BAJ. The diagnosis and treatment of infection in the burn patient. Burns Incl Therm Inj. 1984;11(2):79-91.

133. Colon NC, Schlegel C, Chung DH. Chapter 37 - surgical management of complications of burn injury A2. In: Herndon, David N, editor. BTTotal burn care. 4th ed. London: W.B. Saunders; 2012:421-431.e2.

134. Solomkin JS, Mazuski JE, Bradley JS, et al. Diagnosis and management of complicated intra-abdominal infection in adults and children: guidelines by the Surgical Infection Society and the Infectious Diseases Society of America. Surg Infect (Larchmt). 2010; 11(1):79-109.
Therapeutics and Clinical Risk Management

\section{Publish your work in this journal}

Therapeutics and Clinical Risk Management is an international, peerreviewed journal of clinical therapeutics and risk management, focusing on concise rapid reporting of clinical studies in all therapeutic areas, outcomes, safety, and programs for the effective, safe, and sustained use of medicines. This journal is indexed on PubMed Central, CAS,

\section{Dovepress}

EMBase, Scopus and the Elsevier Bibliographic databases. The manuscript management system is completely online and includes a very quick and fair peer-review system, which is all easy to use. Visit $\mathrm{http}: / / \mathrm{www}$.dovepress.com/testimonials.php to read real quotes from published authors. 